\title{
Keanekaragaman Jenis Kantong Semar (Nepenthes spp.) di Kawasan Taman Wisata Alam Baning Kabupaten Sintang Kalimantan Barat
}

\author{
Anggi Nurhadi ${ }^{1}$, Riza Linda ${ }^{1}$, Mukarlina ${ }^{1}$ \\ ${ }^{1}$ Program Studi Biologi, Fakultas MIPA, Universitas Tanjungpura, Jl. Prof. Dr. H. Hadari Nawawi, Pontianak \\ email korespondensi: angginurhadi05@gmail.com
}

\begin{abstract}
Baning Natural Tourism Site located in Sintang district is the habitat of Nepenthes spp. The aim of the study is to determine the spesies and diversity of Nepenthes spp. in Baning Tourism site. The study was conducted in April - May 2017. Nepenthes spp. observation was done in 5 observation locations which was determined randomly based on the homogeneity of Nepenthes in Baning site with the total number of the observation area of $0.096 \mathrm{Ha}$. The results showed that there are 5 spesies of Nepenthes in Baning namely Nepenthes ampullaria, $N$. bicalcarata, $N$. mirabilis, $N$. gracilis, and $N$. x cantleyi. The diversity of Nepenthes spesies in Baning observation areas is to low, with the value of $\mathrm{H}^{\prime}$ ranging from 1,075 to 0.616 .
\end{abstract}

Keywords: Nepenthes, Diversity, Baning Tourism Site.

\section{PENDAHULUAN}

Kalimantan Barat merupakan daerah beriklim tropis yang mempunyai keanekaragaman flora dan fauna yang tinggi. Salah satu jenis flora yang unik dan banyak diperoleh adalah tumbuhan kantong semar (Nepenthes spp.). Kantong semar merupakan tumbuhan yang memiliki beragam variasi warna dan bentuk kantong yang unik menjadikan kantong semar memiliki keindahan yang khas. Hal ini menjadikan kantong semar mempunyai daya tarik sendiri sebagai tanaman hias yang bernilai ekonomi tinggi (Listiawati dan Siregar, 2008).

Kantong semar termasuk jenis tumbuhan yang dilindungi, berdasarkan UU No. 5 Tahun 1990 tentang Konservasi Sumber Daya Alam Hayati dan Ekosistemnya, dan Peraturan Pemerintah No.7 tahun 1999 tentang Pengawetan Tumbuhan dan Satwa (Listiawati dan Siregar, 2008). Semua jenis kantong semar masuk dalam daftar Convention on International Trade in Endangered Species of Wild Flora and Fauna (CITES), dari 103 jenis kantong semar di dunia yang sudah dipublikasikan, dua jenis kantong semar yaitu $N$. rajah dan $N$. khasiana masuk ke dalam kategori Appendix-1. Jenis lainnya berada dalam kategori Appendix-2 yang berarti segala bentuk kegiatan perdagangan sangat dibatasi (CITES, 2001).

Habitat alami kantong semar terancam oleh kebakaran hutan, konversi lahan, dan kegiatan ekspolitasi kantong semar untuk tujuan komersil. Potensi ancaman kelestarian kantong semar juga terjadi di kawasan-kawasan konservasi yang di sebabkan oleh aktifitas manusia berupa pemanfaatan sumber daya alam secara berlebihan. Kawasan Taman Wisata Alam (TWA) Baning merupakan kawasan konservasi yang terletak di Kabupaten Sintang, Kalimantan Barat. Kondisi kawasan TWA Baning telah banyak mengalami perubahan ekosistem. Menurut Yunus (2005) status kawasan hutan Baning pertama kali ditetapkan sebagai Taman Wisata Alam memiliki luas $315 \mathrm{Ha}$ dan sekarang luas kawasan berkurang menjadi 213 $\mathrm{Ha}$ berdasarkan hasil rekontruksi tata batas tahun 1992.

Berkurangnya luas kawasan TWA Baning terjadi akibat adanya sebagian masyarakat yang berdomisili di sekitar kawasan dan menggarap tanah untuk berkebun. Kondisi ekosistem kawasan TWA Baning diperburuk oleh kebakaran yang terjadi di sebagian kawasan pada tahun 1997 mencapai luas 59,5 Ha (Yunus, 2005). Kebakaran tersebut menyebabkan hilangnya potensi flora dan fauna termasuk tumbuhan kantong semar di kawasan TWA Baning.

Tujuan penelitian ini adalah untuk mengetahui keanekaragaman jenis dan pola distribusi kantong semar (Nepenthes spp.) di kawasan TWA Baning Kabupaten Sintang Kalimantan Barat. 


\section{BAHAN DAN METODE}

\section{Waktu dan Tempat Penelitian}

Penelitian ini dilaksakan dari bulan April-Mei 2017 yang meliputi pengambilan data, identifikasi, pengolahan data, dan penyusunan hasil. Tempat penelitian di kawasan Taman Wisata Alam Baning (TWA Baning) Kabupaten Sintang, Kalimantan Barat.

\section{Deskripsi Lokasi Penelitian}

Kawasan Hutan TWA Baning merupakan daerah datar, dengan tofografi dataran rendah dan tidak

Tabel 1.. Lokasi Pengamatan di Kawasan TWA Baning berbukit. Kawasan hutan TWA Baning umumnya memiliki kondisi tanah berupa tanah gambut dan tanah gley yaitu tanah berwarna abu sampai putih berstruktur liat dan berdebu. Kondisi umum vegetasi didominasi oleh Dipterocarpaceae.

\section{Cara Kerja}

Penentuan Lokasi Penelitian

Pengamatan kantong semar dilakukan pada 5 lokasi pengamatan yang ditentukan secara acak berdasarkan homogenitas kantong semar di Kawasan Taman Wisata Alam Baning.

\begin{tabular}{|c|c|c|}
\hline $\begin{array}{c}\text { Lokasi Pengamatan } \\
\text { ke- }\end{array}$ & Titk Koordinat & Keterangan \\
\hline $\mathrm{I}$ & $00^{\circ} 04^{\prime} 00,,^{\prime} \mathrm{LU}-111^{\circ} 30^{\prime} 28,9^{\prime \prime} \mathrm{BT}$ & $\begin{array}{l}\text { Tanahnya berupa tanah gambut yang dengan vegetasi } \\
\text { didominasi oleh jenis meranti (Sorea sp.), jelutung (Diera } \\
\text { sp.), dan rengas (Gluta sp.) }\end{array}$ \\
\hline II & $00^{\circ} 04^{\prime} 20,5^{\prime}$ ' LU - $111^{\circ} 30^{\prime} 28,3^{\prime}$ ' BT & $\begin{array}{l}\text { Tanahnya berupa tanah gambut dengan vegetasi } \\
\text { didominasi oleh jenis meranti (Sorea } \text { sp.), jelutung (Diera } \\
\text { sp.), rengas (Gluta } \text { sp.), dan pulai (Alstonia } \text { sp.) }\end{array}$ \\
\hline III & $00^{\circ} 04^{\prime} 33,5^{\prime}$ ' LU - $111^{\circ} 30^{\prime} 26,7^{\prime}$ ' BT & $\begin{array}{l}\text { Tanahnya berupa tanah gambut dengan kondisi vegetasi } \\
\text { didominasi oleh jenis meranti (Sorea sp.) dan rengas (Gluta } \\
\text { sp). }\end{array}$ \\
\hline IV & $00^{\circ} 04^{\prime} 04,8^{\prime \prime} \mathrm{LU}-111^{\circ} 30^{\prime} 56,2^{\prime}{ }^{\prime} \mathrm{BT}$ & $\begin{array}{l}\text { Tanahnya berupa tanah berwarna abu sampai putih } \\
\text { berstruktur liat dan berdebu dengan kondisi vegetasi } \\
\text { didominasi oleh paku resam (Gleichenia linearis), beriang } \\
\text { (Ploiarium alternifolium) dan beberapa tumbuhan semak }\end{array}$ \\
\hline $\mathrm{V}$ & $00^{\circ} 04^{\prime} 16,9^{\prime \prime} \mathrm{LU}-111^{\circ} 30^{\prime} 11,8^{\prime \prime} \mathrm{BT}$ & $\begin{array}{l}\text { Tanahnya berupa tanah gambut dengan vegetasi yang } \\
\text { didominasi oleh jenis meranti (Shorea sp.), jelutung dan } \\
\text { rengas (Gluta sp.) }\end{array}$ \\
\hline
\end{tabular}
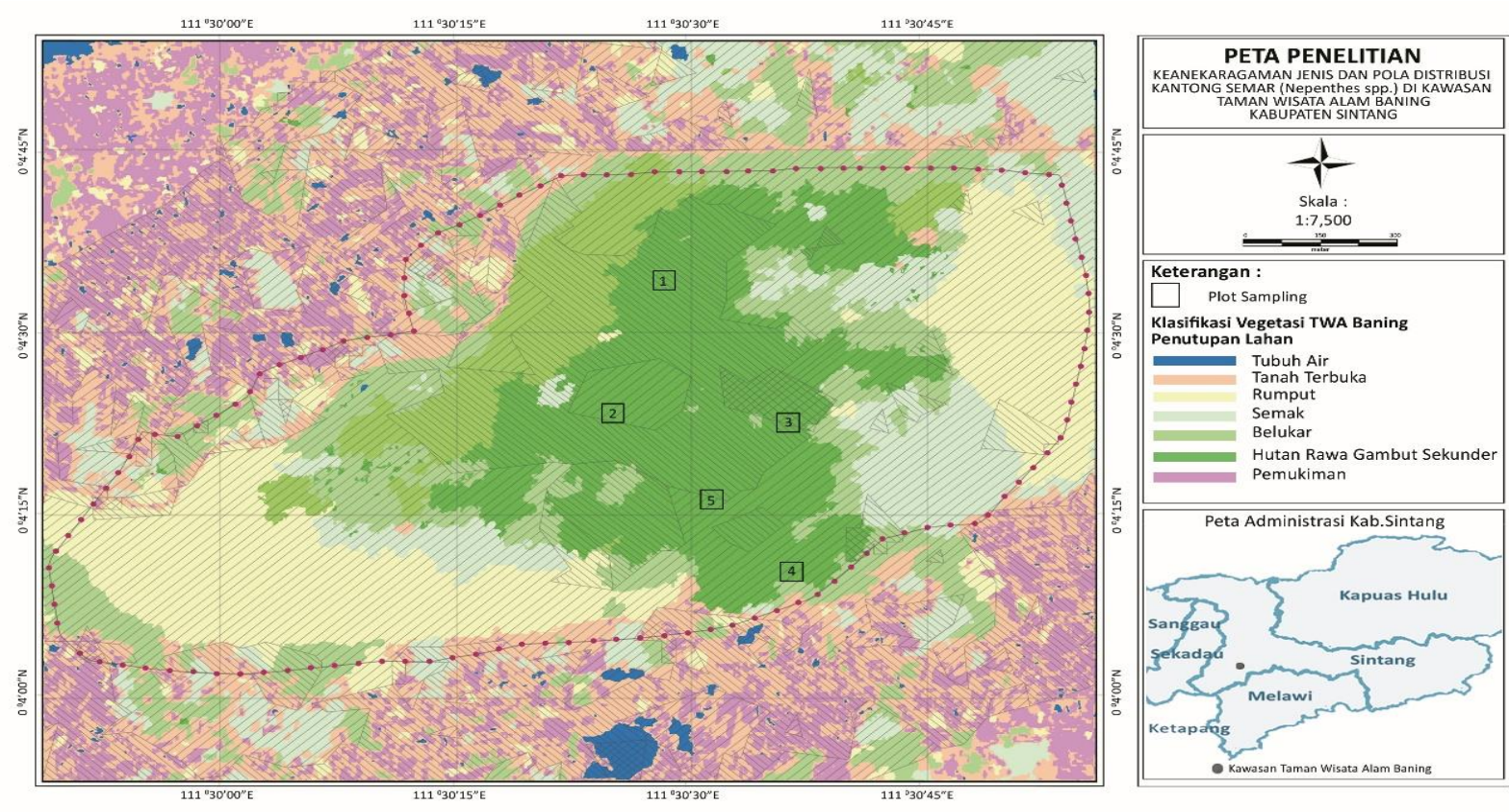

Gambar 1. Peta Penelitian 


\section{Pengambilan Sampel}

Pengamatan kantong semar dilakukan dengan teknik analisis vegetasi menggunakan plot MullerDombois dan Ellenberg (1974) dalam Ilma et al. (2014). Plot berbentuk petak ganda yang diletakan secara sistematik. Setiap lokasi pengamatan (Gambar 1) dibuat 12 petak kuadrat ukuran $2 \times 2 \mathrm{~m}$ dengan jarak antara petak adalah $5 \mathrm{~m}$. Kemudian dilakukan pengulangan sebanyak 4 kali pada setiap lokasi pengamatan sehingga total area pengamatan seluas $0,096 \mathrm{Ha}$.

\section{Pengukuran Faktor Lingkungan Abiotik}

Pengukuran faktor lingkungan abiotik meliputi suhu udara, kelembaban udara, kelembaban tanah, pH tanah, dan intensitas cahaya. Pengukuran masing-masing faktor lingkungan abotik dilakukan sebanyak 3 kali pada masing-masing lokasi penelitian.

\section{Analisis Data}

Kerapatan, Frekuensi, dan Indeks Nilai Penting Perhitungan nilai kerapatan, frekuensi, dan indeks nilai penting menggunakan persamaan sebagai berikut:

1. Kerapatan

a. Kerapatan (K)

$$
\mathrm{K}=\frac{\text { Jumlah individu suatu jenis }}{\text { Luas petak contoh }}
$$

b. Kerapatan Relatif (KR)

$$
\mathrm{KR}=\frac{\text { Kerapatan suatu jenis }}{\text { Kerapatan seluruh jenis }} \times 100 \%
$$

2. Frekuensi (F)

a. Frekuensi suatu jenis $(\mathrm{F})$

$$
\mathrm{F}=\frac{\text { Jumlah petak didapatkan suatu jenis }}{\text { Jumlah seluruh petak contoh }}
$$

b. Frekuensi Relatif suatu jenis (FR)

$$
\mathrm{FR}=\frac{\mathrm{F} \text { suatu jenis }}{\mathrm{F} \text { seluruh jenis }} \times 100 \%
$$

3. Indeks nilai penting (INP)

$$
\mathrm{INP}=\mathrm{KR}+\mathrm{FR}
$$

Indeks Keanekaragaman Jenis $\left(H^{\prime}\right)$, Indeks Kemerataan Jenis $\left(J^{\prime}\right)$, dan Indeks Dominansi Simpson (D) pada Lokasi Pengamatan di Kawasan TWA Baning

Perhitungan indeks keanekaragaman ShannonWienner (H'), indeks Kemerataan Pielou ( $J$ '), dan indeks dominansi Simpson (D) menggunakan persamaan sebagai berikut:

1. Indeks keanekaragaman $\left(\mathrm{H}^{\prime}\right)$

$$
\mathrm{H}^{\prime}=-\sum\{(\mathrm{Pi}) \ln (\mathrm{Pi})\}
$$

2. Indeks kemerataan $\left(J^{\prime}\right)$

$$
\left(J^{\prime}\right)=\frac{\mathrm{H}^{\prime}}{\operatorname{In} \mathrm{S}}
$$

3. Indeks dominansi (D)

$$
\mathrm{D}=\sum\left(\frac{\mathrm{ni}}{\mathrm{N}}\right)^{2}
$$

\section{HASIL DAN PEMBAHASAN}

\begin{tabular}{|c|c|c|c|c|c|c|c|}
\hline \multirow{2}{*}{ No } & \multirow{2}{*}{ Nama Jenis } & \multicolumn{5}{|c|}{ Lokasi Pengamatan } & \multirow{2}{*}{ Jumlah individu } \\
\hline & & I & II & III & IV & $\mathbf{V}$ & \\
\hline 1 & N. ampullaria & 13 & 27 & 34 & 2 & 13 & 89 \\
\hline 2 & N. bicalcarata & 11 & 28 & 15 & 3 & 19 & 76 \\
\hline 3 & N. gracilis & & & & 50 & & 50 \\
\hline 4 & N. $x$ cantleyi & & & & 20 & & 20 \\
\hline \multirow[t]{2}{*}{5} & N. mirabilis & & & & 90 & & 90 \\
\hline & Total & 24 & 55 & 49 & 165 & 32 & 325 \\
\hline
\end{tabular}

\section{Hasil}

Komposisi Jenis Kantong Semar pada Lokasi Pengamatan di Kawasan Taman Wisata Alam (TWA) Baning

Berdasarkan hasil penelitian yang dilakukan di kawasan Taman Wisata Alam (TWA) Baning diperoleh sebanyak 5 jenis kantong semar yang terdiri atas $N$. ampullaria, $N$. bicalcarata, $N$. gracilis, N. mirabilis, dan N. x cantleyi (Tabel 2).

Tabel 2. Jumlah dan jenis kantong semar yang diperoleh pada setiap lokasi pengamatan di Kawasan TWA Baning 
Jenis $N$. ampullaria dan N. bicalcarata adalah jenis kantong semar yang didapatkan pada semua lokasi pengamatan dan $N$. mirabilis merupakan jenis kantong semar yang didapatkan dengan jumlah individu terbanyak yaitu 90 individu dari 325 individu kantong semar yang didapatkan (Tabel 2).
Struktur komunitas kantong semar pada setiap lokasi pengamatan berdasarkan hasil perhitungan dapat dilihat pada Tabel 3 .

Tabel 3. Struktur Komunitas Tumbuhan Kantong Semar pada Setiap Lokasi Pengamatan di Kawasan Twa Baning

\begin{tabular}{|c|c|c|c|c|c|c|}
\hline $\begin{array}{c}\text { Lokasi } \\
\text { Pengamatan }\end{array}$ & Nama Spesies & $\underset{\left(\mathbf{I n d} / \mathbf{m}^{2}\right)}{\mathbf{K}}$ & KR $(\%)$ & $\mathbf{F}$ & $\operatorname{FR}(\%)$ & $\operatorname{INP}(\%)$ \\
\hline \multirow[t]{2}{*}{ I } & N. ampullaria & 0,068 & 54,167 & 0,146 & 50 & 104,167 \\
\hline & N. bicalcarata & 0,057 & 45,833 & 0,146 & 50 & 95,833 \\
\hline \multirow[t]{2}{*}{ II } & N. ampullaria & 0,141 & 49,091 & 0,229 & 42,308 & 91,399 \\
\hline & N. bicalcarata & 0,146 & 50,909 & 0,313 & 57,692 & 108,601 \\
\hline \multirow[t]{2}{*}{ III } & N. ampullaria & 0,177 & $69,388^{*}$ & 0,375 & $66,667^{*}$ & $136,054^{*}$ \\
\hline & N. bicalcarata & 0,078 & 30,612 & 0,188 & 33,333 & 63,946 \\
\hline \multirow[t]{5}{*}{ IV } & N. ampullaria & $0,010 * *$ & $1,212 * *$ & $0,042 * *$ & $4,167 * *$ & $5,379 * *$ \\
\hline & N. bicalcarata & 0,016 & 1,818 & 0,063 & 6,250 & 8,068 \\
\hline & N. gracilis & 0,260 & 30,303 & $0,396^{*}$ & 39,583 & 69,886 \\
\hline & N. mirabilis & $0,469^{*}$ & 54,545 & $0,396^{*}$ & 39,583 & 94,129 \\
\hline & N. $x$ cantleyi & 0,104 & 12,212 & 0,104 & 10,417 & 22,538 \\
\hline \multirow[t]{2}{*}{$\mathrm{V}$} & N. ampullaria & 0,068 & 40,625 & 0,208 & 58,824 & 99,449 \\
\hline & N. bicalcarata & 0,099 & 59,375 & 0,146 & 41,177 & 100,551 \\
\hline
\end{tabular}

Keterangan: (*) Paling tinggi. (**) Paling rendah

K: kerapatan, KR: kerapatan relatif, F: frekuensi, FR: frekuensi relatif, INP: Indeks Nilai Penting

Berdasarkan analisis data $N$. mirabilis yang diperoleh pada lokasi pengamatan IV memiliki nilai kerapatan paling tinggi yaitu sebesar 0,469 individu $/ \mathrm{m}^{2}$. Nepenthes mirabilis dan $N$. gracilis pada lokasi pengamatan IV memiliki nilai frekuensi yang paling tinggi yaitu sebesar 0,396. Nepenthes ampullaria pada lokasi pengamatan III memiliki nilai kerapatan relatif dan frekuensi relatif tertinggi yaitu sebesar 69,388\% dan 66,667\% serta memiliki INP tertinggi dari semua jenis yang diperoleh pada setiap lokasi pengamatan yaitu sebesar 136,054\% (Tabel 3).
Indeks Keanekaragaman Jenis $\left(H^{\prime}\right)$, Indeks Kemerataan Jenis $\left(J^{\prime}\right)$, dan Indeks Dominansi Simpson (D) pada Lokasi Pengamatan di Kawasan TWA Baning

Hasil analisis data memperlihatkan bahwa nilai indeks keanekaragaman jenis $\left(\mathrm{H}^{\prime}\right)$ di kawasan TWA Baning berkisar antara 1,075-0,616 Nilai indeks kemerataan jenis $\left(J^{\prime}\right)$ pada kelima lokasi tersebut berkisar 0,668-1. Sedangkan nilai indeks dominansi Simpson (D) berkisar antara 0,4050,575 (Tabel 4).

Tabel 4. Indeks Keanekaragaman Jenis (H'), Indeks Kemerataan Jenis (J'), dan Indeks Dominansi Simpson (D) pada Lokasi Pengamatan di Kawasan TWA Baning

\begin{tabular}{lccccc}
\hline \multirow{2}{*}{ Indeks } & \multicolumn{5}{c}{ Lokasi Pengamatan } \\
\cline { 2 - 6 } & \multicolumn{1}{c}{ I } & II & III & IV & V \\
\hline Keanekaragaman (H') & 0,690 & 0,693 & $0,616^{* *}$ & $1,075^{*}$ & 0,675 \\
Dominansi (D) & 0,503 & 0,500 & $0,575^{*}$ & $0,405^{* *}$ & 0,518 \\
Kemerataan $\left(J^{\prime}\right)$ & 0,995 & $1,000^{*}$ & 0,889 & $0,669^{* *}$ & 0,974 \\
\hline
\end{tabular}

Keterangan: (*) Paling tinggi. (**) Paling rendah 
Tabel 5. Nilai Rerata Pengkuran Faktor Lingkungan pada Setiap Lokasi Pengamatan di Kawasan TWA Baning

\begin{tabular}{cccccc}
\hline $\begin{array}{c}\text { Lokasi } \\
\text { Pengamatan }\end{array}$ & $\begin{array}{c}\text { pH } \\
\text { Tanah }\end{array}$ & $\begin{array}{c}\text { kelembaban Tanah } \\
(\mathbf{\%})\end{array}$ & $\begin{array}{c}\text { Suhu Udara } \\
\left({ }^{\circ} \mathbf{C}\right)\end{array}$ & $\begin{array}{c}\text { Kelembaban Udara } \\
(\boldsymbol{\%})\end{array}$ & $\begin{array}{c}\text { Intensitas Cahaya } \\
(\text { lux })\end{array}$ \\
\hline I & 3,97 & 75,67 & 29,17 & 67,67 & $157-412$ \\
II & 3,90 & 74,33 & 27,57 & 72,33 & $192-600$ \\
III & 3,93 & 73,00 & 29,00 & 72,67 & $110-435$ \\
IV & 5,07 & 60,33 & 30,60 & 61,33 & $1760-30.600$ \\
V & 4,47 & 81,33 & 28,93 & 72,67 & $148-530$ \\
\hline
\end{tabular}

\section{Pembahasan \\ Komposisi Jenis Kantong Semar pada Lokasi Pengamatan di Kawasan Taman Wisata Alam (TWA) Baning \\ Jenis kantong semar yang ditemukan pada kawasan gambut di lokasi pengamatan I, II, III, dan V sebanyak 2 jenis, yaitu $N$. ampullaria dan $N$. bicalcarata, sedangkan pada lokasi IV yang memiliki tipe habitat tanah berpasir ditemukan 5 jenis kantong semar (Tabel 2).}

Kondisi vegetasi pada lokasi pengamatan I, II, III, dan $\mathrm{V}$ umumnya ditumbuhi oleh jenis pohon rengas (Gluta sp.), meranti (Shorea sp.), ramin (Gonystylus sp.), dan jelutung (Dyera sp.) (Tabel 1). Jenis kantong semar yang diperoleh pada keempat lokasi pengamatan ini adalah $N$. ampullaria sebanyak 89 individu dan $N$. bicalcarata sebanyak 76 individu.

Karakteristik hutan gambut TWA Baning yang lembap sesuai dengan habitat yang dibutuhkan oleh kantong semar seperti $N$. ampullaria dan $N$. bicalcarata. Menurut Phillipps et al. (2008) dan Clarke (2001) $N$. ampullaria dan $N$. bicalcarata yang terdapat di Pulau Kalimantan banyak ditemukan pada hutan gambut dataran rendah.

Berbeda dari keempat lokasi pengamatan yang didominasi oleh pohon, lokasi pengamatan IV memiliki vegetasi yang didominasi oleh tumbuhan semak seperti beriang (Ploiarium alternifolium.) dan paku resam (Gleichenia linearis). Kantong semar yang diperoleh pada lokasi pengamatan IV adalah $N$. ampullaria, $N$. bicalcarata, $N$. gracilis, $N$. mirabilis, dan N. x cantleyi.

Nepenthes mirabilis merupakan jenis kantong semar yang paling banyak diperoleh sebanyak 90 individu. Menurut Mansur (2007) jenis kantong semar dataran rendah seperti $N$. mirabilis dan $N$. gracilis banyak ditemukan pada kawasan hutan yang terbuka. Hal ini sesuai dengan penelitian Rudiansyah (2009) di kawasan hutan Dusun Air Merah Desa Ngarak kecamatan Mandor Kabupaten Landak, Putra (2009) di hutan Bagan Lari Desa
Sungai Nanjung Kecamatan Matan Hilir Selatan Kabupaten Ketapang, dan Purnomo (2006) di Taman Wisata Alam Bukit Kelam yang menemukan $N$. mirabilis dan $N$. gracilis di bagian hutan yang terbuka.

Hasil penelitian di Kawasan TWA Baning diperoleh satu jenis kantong semar hibrida alami yaitu $N . \quad x$ cantleyi sebanyak 20 individu. Berdasarkan pengamatan morfologi $N$. $x$ cantleyi yang mengacu kepada Listiawati dan Siregar (2008) dan Phillipps et al. (2008), morfologi kantong bawah $N$. $x$ cantleyi yang diperoleh di kawasan TWA Baning memiliki bagian bawah sampai ke bagian tengah yang menyerupai kantong $N$. bicalcarata, bagian tengah sampai ke bagian atas menyerupai kantong $N$. gracilis, bentuk peristome menyerupai peristome pada kantong $N$. gracilis, penutup kantong menyerupai tutup kantong $N$. bicalcarata, dan bentuk morfologi yang paling menonjol adalah adanya dua taring khas kantong $N$. bicalcarata pada bagian bawah penutup kantong $N . x$ cantleyi. Menurut Phillipps et al. (2008) kehadiran suatu jenis hibrida alami kantong semar di suatu habitat dapat terjadi apabila pada habitat tersebut dijumpai dua atau lebih jenis kantong semar.

Struktur Komunitas Tumbuhan Kantong Semar pada Setiap Lokasi Pengamatan di Kawasan TWA Baning

Berdasarkan analisis data jenis $N$. mirabilis memiliki nilai kerapatan sebesar $0,468 \mathrm{ind} / \mathrm{m}^{2}$ dan kerapatan relatifnya (KR) sebesar $54,545 \%$ (Tabel 3). Nepenthes mirabilis dan $N$. gracilis yang diperoleh pada lokasi pengamatan IV memiliki nilai frekuensi jenis paling tinggi dibandingkan jenis lainnya yaitu sebesar 0,396 (Tabel 3).

Tingginya nilai kerapatan dan frekuensi $N$. mirabilis yang diperoleh pada lokasi pengamatan IV menunjukkan bahwa kondisi habitat mendukung pertumbuhan jenis ini. Berdasarkan hasil pengukuran faktor lingkungan pada lokasi pengamatan IV diperoleh rerata $\mathrm{pH}$ tanah sebesar 5,07 , kelembaban tanah sebesar $60,33 \%$, suhu 
udara sebesar $30,60^{\circ} \mathrm{C}$, kelembaban udara sebesar $61,33 \%$, dan intensitas cahaya berkisar 1760 (range 2000) - 30.600 lux (range 50.000) (Tabel 5), kondisi ini mendukung pertumbuhan generatif $N$. mirabilis. Menurut Smythies (1965) dalam Adam et al. (1991) pertumbuhan dan produksi bunga pada kantong semar terkait dengan intensitas cahaya. Beberapa jenis kantong semar mampu tumbuh subur pada intensitas cahaya penuh dan beberapa jenis kantong semar yang ditemukan hidup dibawah naungan kanopi pohon Dipterocarpaceae jarang menghasilkan bunga.

Nilai kerapatan $N$. ampullaria pada lokasi pengamatan I, II, III, dan V berkisar antara 0,0680,177 individu $/ \mathrm{m}^{2}$ dan kerapatan $N$. bicalcarata berkisar antara 0,057-0,146 (Tabel 3) yang menunjukkan bahwa kedua jenis ini memiliki daya dukung habitat yang sama untuk tumbuh dan berkembang. Menurut Clarke (2001) jenis-jenis kantong semar dapat tumbuh dengan baik apabila telah mengalami penyesuaian dengan kondisi lingkungannya. Jika jenis kantong semar tumbuh pada lingkungan yang sesuai maka jenis-jenis kantong semar akan tumbuh dan memiliki jumlah populasi yang besar dalam komunitasnya.

Jenis $N$. ampullaria yang terdapat pada lokasi pengamatan III memiliki INP tertinggi, yaitu sebesar 136,054\% (Tabel 3). Tingginya indeks nilai penting yang dimiliki $N$. ampullaria menunjukkan bahwa jenis ini memiliki peran penting pada komunitas.

Indeks Keanekaragaman $\left(H^{\prime}\right)$ dan Indeks Kemerataan $\left(J^{\prime}\right)$ dan Indeks Dominansi $(D)$ pada Lokasi Pengamatan di Kawasan TWA Baning

Hasil analisis data memperlihatkan bahwa nilai indeks keanekaragaman jenis $\left(\mathrm{H}^{\prime}\right)$ di kawasan TWA Baning berkisar antara 1,075-0,616 (Tabel 4). Nilai $\mathrm{H}^{\prime}$ pada lokasi pengamatan IV lebih tinggi dibandingkan dengan lokasi pengamatan lainnya. Hal ini disebabkan oleh jumlah jenis dan individu kantong semar yang diperoleh pada lokasi pengamatan IV lebih banyak.

Menurut Odum (1993) semakin tinggi nilai $\mathrm{H}^{\prime}$ berarti semakin beragam jenis yang terdapat pada suatu komunitas. Menurut Odum (1993) nilai $\mathrm{H}^{\prime}$ dipengaruhi oleh jumlah jenis yang ditemukan dan tingkat kemerataan individu antar jenis. Lokasi pengamatan I, II, III, dan V memiliki tingkat kemerataaan individu lebih tinggi dibandingkan dengan lokasi pengamatan IV namun jumlah jenis yang ditemukan lebih sedikit yaitu sebanyak 2 jenis (Tabel 2), sehingga nilai $\mathrm{H}^{\prime}$ pada keempat lokasi pengamatan tersebut tergolong rendah.
Tingkat keanekaragaman jenis pada setiap lokasi penelitian dilihat pula dari Indeks kemerataan $\left(J^{\prime}\right)$. Nilai $J^{\prime}$ pada lokasi pengamatan I, II, III, dan V berkisar antara 0,889-1 (Tabel 4). Menurut Krebs (1989) nilai indeks yang mendekati angka 1 menunjukkan bahwa penyebaran individu antar jenis semakin merata. Sedangkan pada lokasi pengamatan IV memiliki nilai indeks kemerataan lebih rendah dibandingkan 4 lokasi pengamatan lainnya sebesar 0,668 yang menunjukkan adanya jumlah individu yang terpusat pada beberapa jenis.

Hal ini dapat diartikan ada beberapa jenis yang memiliki jumlah individu relatif banyak, sementara beberapa jenis lainnya memiliki jumlah individu relatif sedikit. Hasil pengamatan pada lokasi IV diperoleh jenis $N$. mirabilis, $N$. gracilis, dan $N . x$ cantleyi memiliki jumlah individu lebih banyak dibandingkan dengan jenis $N$. ampullaria dan $N$. bicalcarata (Tabel 2).

Indeks Dominansi jenis (D) menggambarkan pola dominansi suatu jenis terhadap jenis lainnya dalam suatu komunitas. Hasil perhitungan nilai D jenis kantong semar pada lokasi pengamatan di TWA Baning berkisar antara 0,405- 0,575 (Tabel 4), menurut Krebs (1989) nilai $\mathrm{D}=0,31-0,60$ tergolong sedang, hal ini disebabkan oleh tingkat dominansi terpusat pada beberapa jenis kantong semar. Menurut (Odum, 1993) nilai D berkisar antara $0-1$, semakin tinggi nilai $\mathrm{D}$ maka pola penguasaan terpusat pada jenis-jenis tertentu saja, sebaliknya semakin rendah nilai $D$ menggambarkan pola penguasaan jenis-jenis dalam komunitas tersebut relatif menyebar pada masingmasing jenis.

\section{DAFTAR PUSTAKA}

Adam, JH, Wilcock, CC, \& Swaine, MD, 1991, 'The Ecology and Distribution of Bornean Nepenthes', Journal okripsisf Tropical Fores Science, vol. 5, no. 1

CITES, 2001, 'Carnivorous Plant Checklist, The Trustees of Royal Botanic Gardens Kew, Inggris

Clarke, C, 2001, Nepenthes of Borneo, Natural Publication (Borneo), Sabah

Ilma, S, Rohman, F, \& Ibrohim, 2014, 'Analisis Vegetasi Nepenthes spp. di Hutan Penelitian Universitas Borneo Tarakan', Prosiding Seminar Biologi, vol. 11, no. 1, hal 285

Krebs, CJ, 1989, Ecological Methodology, Harper Collins Publisher, New York 
Protobiont (2018) Vol. 7 (3) : 111 -117

Listiawati, A, \& Siregar, C, 2006, Entuyut (Nepenthes) Asal Kalimantan Barat, Untan press, Pontianak

Mansur, M, 2007, Kantong Semar yang Unik, Penerbit Swadaya, Jakarta

Odum, EP, 1993, Dasar-Dasar Ekologi, Gadjah Mada University Press, Yogjakarta

Phillipps, A, Lam, A, \& Lee, CC, 2008, Pitcher Plant of Borneo, Natural Publication (Borneo), Sabah

Purnomo,TES, 2006, Studi Keanekaragaman dan Penyebaran Kantong Semar (Nepenthes spp.) di Kawasan Taman Wisata Alam Bukit Kelam Kabupaten Sintang, Skripsi, Fakultas Kehutanan, Universitas Tanjungpura, Pontianak

Putra, IY, 2009, Inventarisasi Jenis Kantong Semar (Nepenthes spp.) di Hutan Bagan Lari Desa Sungai Nanjung Kecamatan Matan Hilir Selatan Kabupaten Ketapang, Skripsi, Fakultas Pertanian, Universitas Tanjungpura, Pontianak

Rudiansyah, Y, 2009, Inventarisasi Jenis Kantong Semar (Nepenthes spp.) di Kawasan Hutan Dusun Air Merah Desa Ngarak Kecamatan Mandor Kabupaten Landak, Skripsi, Fakultas Pertanian, Universitas Tanjungpura, Pontianak

Yunus, L, 2005, Metode Penilaian Ekonomi Kerusakan Lingkungan Akibat Kebakaran Hutan dan Lahan (Studi Kasus di Kabupaten Sintang Kalimantan Barat), Disertasi, Institut Pertanian Bogor, Bandung 